waves into a lower velocity zone below. In fact, calculations suggest that the $S$ wave velocity decreases from about $4.7 \mathrm{~km} \mathrm{~s}^{-1}$ at the top of the mantle to about $4.4 \mathrm{~km} \mathrm{~s}^{-1}$ at $300 \mathrm{~km}$, followed by a more rapid decrease to a value of $3.8 \pm 0.2 \mathrm{~km} \mathrm{~s}^{-1}$. Below $800 \mathrm{~km}, \mathrm{~S}$ waves are highly attenuated.

From these and other results, the most up-to-date picture of the lunar interior is then as follows:

- Zone 1: crust. This uppermost zone is $50-60 \mathrm{~km}$ thick in the region of the Apollo 12 and 14 stations and has seismic velocities consistent with plagioclase-rich material. The top few hundred metres is highly pulverised.

- Zone 2: upper mantle. This zone is about $250 \mathrm{~km}$ thick and has a $P$ wave velocity of about $8.1 \mathrm{~km} \mathrm{~s}^{-1}$ which probably decreases slightly with depth. The seismic data are consistent with mineral assemblages comprising olivines (mostly) and pyroxenes (partly). The temperature gradient at the top of this zone is calculated to be $2-5^{\circ} \mathrm{C}$ $\mathrm{km}^{-1}$.

- Zone 3: middle mantle. This is a zone with reduced $\mathrm{S}$ wave velocity and extends from $300 \mathrm{~km}$ to $800 \mathrm{~km}$. Deep moonquakes occur at the base of it. - Zone 4: lower mantle. This zone below $800 \mathrm{~km}$ is marked by high $\mathrm{S}$ wave attenuation and is possibly partially molten (as the terrestrial asthenosphere).

- Zone 5: core. This zone has a radius of $170-360 \mathrm{~km}$ and is marked by a greatly reduced $\mathrm{P}$ wave velocity. Molten?

\section{Microclimate of open shade habitat}

from Peter D. Moore

Extreme habitats and the morphological and physiological adaptations necessary for life within them have always been more popular topics for study than have moderate conditions. It is becoming apparent, however, that immediate habitats, or ecotones, often have interesting attributes which make them worthy of special attention. An example of such a situation is provided by the study of open and shaded habitats.

For many years it has been conventional to classify plants into sundemanding (heliophytes) and shaderequiring (sciophytes), and a great deal of research has been carried out both upon the physiological adaptation of these plants (for example, Björkman and Holmgren, Physiologia Pl., 16, 889; 1963; Björkman, ibid., 19, 854; 1966) and upon the light climates of shade habitats (for example, Anderson, in Plant Photosynthetic Production, edit. by Sestak, Catsky and Jarvis, Junk, The Hague, 1971). Little atten- tion, however, has been given to intermediate situations, which can be termed 'open shade'.

A study of the open shade habitat from the microclimatic point of view has now been made by Stoutjesdijk (Acta bot. neerl., 23, 125; 1974). Surface temperatures on the north side of a patch of hawthorn (Crataegus monogyna) scrub in a Dutch sand-dune system were found to be as much as $10^{\circ} \mathrm{C}$ below those of ambient air. Although surfaces temperatures above ambient are commonplace, to find surfaces considerably below ambient at midday is extremely unusual and can only be explained in terms of the overall energy balance in these situations. At $11.30 \mathrm{~h}$ on a bright day in September, Stoutjesdijk found the surface temperature to be $9.1^{\circ} \mathrm{C}$ whereas ambient air was $15^{\circ} \mathrm{C}$. Incoming radiant energy was in the form of diffuse solar radiation $\left(0.1 \mathrm{cal} \mathrm{cm}^{-2} \mathrm{~min}^{-1}\right)$ and long wave radiation from the sky $\left(0.395 \mathrm{cal} \mathrm{cm}^{-2}\right.$ $\left.\min ^{-1}\right)$. Radiant energy loss was accounted for by reflection $(0.01 \mathrm{cal}$ $\left.\mathrm{cm}^{-2} \mathrm{~min}^{-1}\right)$ and by long wave radiation $\left(0.523 \mathrm{cal} \mathrm{cm}^{-2} \min ^{-1}\right)$. The net outcome of this situation is negative energy balance of $-0.038 \mathrm{cal} \mathrm{\textrm {cm } ^ { - 2 }}$ $\min ^{-1}$, this being largely the result of the high long-wave radiation losses. The negative radiation budget is rather weak, however, and cannot fully account for the low surface temperature. The true energy budget is more strongly negative because of latent heat losses from the surface during the evaporation of dew; this explains the low surface temperatures.

This type of energy balance situation can occur only in open shade, for only here are long-wave losses large in comparison with gains and evaporation can take place at a rate sufficient to maintain high latent heat losses. Surface temperatures were found to be below ambient in daytime throughout the year, but differences were least in June and July (shading effects diminished) and greatest in late summer (strong shading and considerable dew formation).

Some work has been carried out on the influences of leaf canopies upon the spectral quality of light, but most of this has been concentrated on fairly dense canopies (see, for example, Federer and Tanner, Ecology, 47, 555; 1966; Daynard, Can. J. Bot., 47, 1989; 1969; Acta bot. neerl., 21, 185; 1972). These studies have shown that the rate of visible to far-red radiation decreases considerably as shading increases. Measurements by Stoutjesdijk in his open shade habitat showed that there was a far better penetration of photosynthetically usable light $(<700 \mathrm{~nm})$ than in the deep shade beneath hawthorn scrub.

Open shade habitats, then, provide an interesting combination of physical conditions-low daytime temperatures (with consequent high-relative humidities) and moderate photosyntheticallyeffective light levels. Undoubtedly some plant species characteristic of open shade habitats, such as, for example, Mnium undulatum, Rhytidiadelphus triquetrus, find such conditions to their liking. Some anomalous plant distributions may also be explicable in terms of this unusual combination of microclimatic factors. For example, it may be that the steep, north facing scarp slopes of the South Downs provide a similar microclimatic habitat to Stoutjesdijk's 'open shade'. In which case it might explain the persistence in such situations of montane bryophyte species, such as Rhacomitrium lanuginosum, which are known to require high humidities, fairly low temperatures and moderately high light intensities for their survival.

\section{Nature of Hoag's object}

by John Gribbin

IT is now nearly a quarter of a century since Hoag discovered a remarkable astronomical object which appeared to be a "perfect halo" surrounding a diffuse nucleus. But only now is Hoag's object, as it has come to be known, receiving the attention which its peculiarity merits. According to O'Connell, Scargle and Sargent (A strophys. J., 191, $61-62 ; 1974)$ the object is certainly worth investigating and "one of the more exotic possible interpretations" is that the ring is the image of a background galaxy produced by a gravitational lens effect.

Hoag's object is clearly visible on $S k y$ Survey prints (at $\alpha=15$ h $15.0 \mathrm{~min}$; $\delta=+21^{\circ} 46^{\prime}$ ) but it has not previously been studied in detail. The core of the object is a fuzzy circle $6^{\prime \prime}$ in diameter, and the surrounding blue ring or annulus has inner diameter 28" and outer diameter $45^{\prime \prime}$ with an axial ratio of $0.93 \pm 0.05$. The ring is structureless, and there is no sign of connecting material bridging the gap between core and annulus.

In the study now reported by O'Connell et al. new information has been obtained from spectrograms taken with the 200-inch telescope and the Lick 120-inch. The observed redshift of $12,740 \mathrm{~km} \mathrm{~s}^{-1}$ and an assumed Hubble constant of $75 \mathrm{~km} \mathrm{~s}^{-1} \mathrm{Mpc}^{-1}$ imply a distance of $170 \mathrm{Mpc}$, corresponding to a linear diameter of $5 \mathrm{kpc}$ for the core and inner and outer radii of 23 $\mathrm{kpc}$ and $37 \mathrm{kpc}$ for the ring.

Almost all of the properties of the core seem to be in line with those expected for compact galaxies, but there seems little doubt that the ring is "an 